\title{
The Essence of Kaidzen's Basic Elements
}

\author{
Maria Sergeevna Rybyantseva ${ }^{1}$ \\ Elena Nikolaevna Klochko² \\ Olga Michailovna Ignatova ${ }^{3}$ \\ ${ }^{1}$ Kuban state agrarian University, \\ ${ }^{2}$ Southern Institute of Management, \\ 3Russian University of Cooperation Russian Federation; Email: magadan.79@mail.ru
}

Doi:10.5901/mjss.2015.v6n5s3p25

\section{Abstract}

Kaidzen as a system lays at the crossroads of accounting and management. It consists of elements that can be divided into groups: theoretical, methodical and structural. Theoretical elements define the methodological essence and consist of subjects, objects, principles, functions, etc. Objects are selected from a varus-kagen position. The following principles are allocated: integration, hierarchy and feedback, continuity and consistency, the basis of mentality with a universal approach, a new quality of leadership, process of thinking, elimination of stereotypes, deviations control from a standard process, the dynamic changes of tools and targets, identification and personification, the principle of a «baton». Classification identifies are allocated: aspects of the review, areas for improvement, resources, spheres and so on. A list of classical kaidzen tools is pointed out within the classification according to the degree of modernity. Structural elements of kaidzen reflect semantic content of controlling and the lean production. Lean production is considered in the unity of the quality management system and process method.

Keywords: kaidzen, controlling, lean production, system.

\section{Introduction}

One of the aphorisms of the known economist E. Deming says: «Improving is not a must. Survival is voluntary» (Kanban and "just in time" at Toyota: management begins at the workplace / translated from English, 2014). The system of kaidzen was developed in order to improve management approaches, optimize production processes, improve information role of the management information.

Kaidzen system can be defined as the process of improving all aspects of the firm`s activity, and optimization of the processes of achieving long-term competitive advantages.

The aim of kaidzen - is improving the processes taking place in the framework of the company's activities by eliminating losses in the presence of moral satisfaction from the work of employees of all parts of the management hierarchy, leveling the entropy, improving products` quality and achieving competitive advantages.

\section{Methods and Materials}

In the classification of the system of kaidzen the following items can be allocated:

1) By the aspects of the review:

- Ideology - thinking primarily of senior management, aimed at improving all aspects of the activities of the organization.

- Tool - practical design, allowing the realization the ideology of kaidzen in practice.

2) By the areas of improvement:

- Management models - approaches to improving processes, structure of the company, etc.

- Information systems - changes of accounting approaches, expansion of the generated data list to make the necessary management decisions.

These positions are related, since one needs the administrative influence to organize information flows, the formation of slotting (which employee generates data, at what time, who provided information, etc.).

3) Resources: kaidzen labor; material; of fixed assets, etc. 
4) Areas: logistics; production; sales; financial investment, etc.

5) By the managers` hierarchy: senior management; middle management and ordinary employees.

Senior management is focused on improving the strategic scale, i.e., it suggests solutions to global problems. This does not exclude the presence of feedback between the employees of the organization though. Ordinary employees improve current processes, i.e., they are working on a tactical level, but private changes should take place within a selected top management strategy.

6) By the results of the system 's operations:

- Indicators that can be expressed in quantitative or monetary terms;

- Qualitative improvement (optimization) - figures that do not have a quantitative value or expression, but reflecting the strengthening of the competitive position of the organization;

7) By the horizon of the consideration:

- Focus on the process (focus on the present moment);

- Focus on the result (emphasis on the goal);

According to Masaaki Imai, senior management, if focused only on the process, risks to remain without long-term strategy and to miss new ideas and innovations, by just instructing employees how to perform each step. The resultoriented manager is more flexible when setting goals and can think strategically. However, he or she is able to ignore the mobilization and redeployment of resources in the implementation of the chosen strategy (Kizim, 2012).

8) By the performed functions: improvement planning; analysis; control; information generating; counseling; coordination (actions and information flows);

9) By the main stages of the product's life cycle: market introduction, growth, maturity, decline;

- By the stage of the organization `s life cycle:

- Kaidzen in terms of narrowed production (stagnation);

- General production;

- Scaling up.

10) By the degree of radical change (using the terminology by Jones $D$. and J. Womack):

- Breakthrough kaidzen, flow kaidzen, system kaidzen (kaykaku) - a radical improvement of the process aimed at the illumination of "mud" (the losses);

In his work, Chika V.A. (24) the type encountered in this Kaidzen kind of improvement is called proactive improvement; it leads to the implementation of the new directions in the form of new products, processes, and others.

- Targeted kaidzen, the kaidzen of the process - constant and continuous improvement activities in order to increase value and reduce the «mud».

Improvements emerging in this kind of kaidzen are divided into two types:

- Operational improvement (elimination of deviations from the standard without a thorough analysis of the causes);

- Reactive improvement (influence on the cause of the deviation).

11) By the degree of modernity:

- This is a classic kaidzen - opposable to innovations, the toolkit is limited, statistical methods are dominant;

Kaidzen tools for solving problems in accordance with the work of Masaaki Imai are divided into seven statistical tools (Pareto diagrams, charts the causes and results, histograms, control charts, scatter diagrams, charts, checklists) and «seven new» (chart connections), chart affinity, tree diagrams, matrix diagram, chart analysis matrix data, a block diagram of the decision making process, arrow diagram).

- Modern kaidzen, including innovation and all possible instruments of controlling and lean manufacturing for solving problems.

12) By the processes' categories:

- $\quad$ Basic (purchasing, production, sales);

- Providing (administrative and economic (tactical aspect), juridical, accounting software, etc.);

- Management (financial management, marketing and innovation, strategic management).

13) By product categories:

- Services (transport for example);

- Software (computer program for example);

- Technical means;

- Recyclable materials.

Many products comprise elements belonging to different generic product categories. Whether the product is a service, software or hardware or processed material depends on the dominant element (Raizberg, 2008 \& Novikov, et al., 
2015).

14) By the scale of change (innovation) (Uvarov, 2012):

- Technology or product (carried out not only in response to the changing needs and expectations of customers and other stakeholders, and anticipate potential changes in the environment of the organization and the product life cycle);

- Processes (innovative techniques to ensure the product life cycle or innovations to improve the stability of processes and reduce their variability);

- In the organization (a change in the legal form and organizational structure);

- The organization's management system (innovation for competitiveness and the use of new capabilities in the event of changes in the organization's ranks).

Dedicated 15 classification bases kaidzen reflect different aspects of the system.

As a system kaidzen consists of a number of parts, called elements (components). Basically, kaidzen lays at the joint of management (Kobersy, et al., 2015) and accounting information systems, which results in its complicated structure.

Basic level kaidzen provides research, development and systematization of the following elements:

1) General theoretical (approaches, interpretations, subjects, objects, principles and functions).

2) Structure (controlling and lean production).

3) Methodology (Kaidzen tools).

Let's review the general theoretical elements of kaidzen.

Kaidzen's control subjects are executives, managers of all levels empowered to make decisions.

Objects can be grouped together by many bases.

In particular, the grouping can be carried out by the areas of possible problems: organizational structure; revenues, expenses, assets, liabilities, capital; the company's brand; data/knowledge base (artificial intelligence); employee satisfaction; downtime; control technologies; customer base (Beloglazov Denis, 2015).

Such grouping best of all corresponds to the essence of Kaidzen and, in particular, is defined by the term varuskagen reflecting the situation, which is not a problem yet, but is not perfect either. If left unattended, it can become a source of serious problems.

The classification can be changed depending on the task.

During the kaidzen system forming in the organization one should be guided by several principles:

- Integration.

- Hierarchy and feedback.

- Succession and consistency.

- Basing of mentality with the universal approaching.

- A new quality of leadership.

- Procession thinking.

- Elimination of stereotypes.

- Control of deviations from the standard process.

- Dynamic changes in instruments and targets.

- Identification and personalization.

- The principle of «baton».

Kaidzen is based on several principles, first of all - integration, which can be viewed from two perspectives: the organizational and accounting. Kaidzen system should not be divorced from the information system of the organization. Any improvement is based on the information, so should be conducted in parallel with a change in accounting approaches and transformation of information flows.

Organizational integration is the involvement of managers of all levels in the process of improving and that any improvement requires change management approaches and structural rearrangements, the introduction of new software products. Thus, the transformation affects not only the factors of production but also the information and management.

The next principle is the hierarchy and feedback, whereby differentiated approaches to improving the levels of management, and it include not only top management but also the main production workers performing core manufacturing operations. It is a mistake to assume that the vector perfection directed only from the top down, that is, from senior management to employees. It was at the «lower» level of management employees imagine in detail the process and determine the reasons for failure, as well as ways to optimize processes made. If the leadership is locked in an intellectual and status snobbery, it misses an opportunity for improvement. Of course, one can not dispute the fact that the decision of the head is determined that the vertical of power is needed. But, nevertheless, the presence of feedback is 
critical for the successful development organization. Having feedback allows one to direct the efforts of employees at various levels of management to the goals which are same for all employees of the company.

Here is an example of the principle of hierarchy (Kizim, 2012). Top management has the following objectives within the framework of the implementation of kaidzen:

- The introduction of Kaidzen as a corporate strategy;

- Allocation of resources;

- Determination of the policy, and cross-functional Kaidzen goals;

- Construction of systems, procedures and structures that contribute to kaidzen.

- At the level of implementation of workers' kaidzen provides:

- Submit proposals and participate in the work of small groups, develop proposals for optimizing processes;

- $\quad$ Maintenance of discipline in the area;

- Constant self-development, acquiring the problem-solving skills;

- Improving the skills and performance through mutual learning.

Obviously, tasks which are being solved under the Kaidzen strategy depend on the level of management, but they must be subordinated to a single goal agreed with the selected strategic goal of the company (the objectives and tasks of different levels).

Succession is the evolutionary nature of kaidzen. This system, incorporating all the latest developments in the theory and practice, does not reject the theoretical and practical development of the past, keeping their rational seed. There is no idea of change just for change's sake. The main goal - is to move forward, perfecting (which is impossible with a negative attitude to the past experience).

Consistency appears in that kaidzen affects all aspects of life in the organization, control the most important processes in all stages of the value chain. The holistic set of interrelated elements called «Kaidzen umbrella».

Consistency is also reflected in the integrated use of three management approaches:

«Insect eyes» - allows one to view objects and processes in the smallest details, and relationships.

«Eagle eyes» - allows one to see a picture of the production as a whole.

«Fish eyes» - allows one to monitor, analyze and forecast the deep, often hidden currents, trends, influences and interactions inaccessible superficial observation.

On the basis of the principle of universality in the mentality of approach reflects the dual nature of kaidzen. Despite the fact that kaidzen is a set of rational approaches that are applicable in any country, traditionally - it is a system, which in some way is an ideology formed taking into account the specifics of the Eastern mentality. An example can be considered different approaches to innovation (Western management) and sustained improvement (Eastern Management). Obviously, we consider the polar points of view, which, however, reflect a fundamentally different approach between the two civilizations.

Specificity of kaidzen is also reflected in national traditions and beliefs when forming its categorical apparatus (i.e., the national term becomes world-wide). Here are some examples:

1) The term «muda», translated as «junk», i.e. any activity for which the customer is not willing to pay (Kireyeva, 2013 \& Krishtal, 2010), refers to actions that do not create value. I.e. cessation of these actions will not affect the quality or the properties of the product, but only lead to a reduction in costs; this category also includes unnecessary improvements;

2) Jidoka (autonomy) - automation of the mind, i.e., development of highly (with a bit of marriage) and constraining processes; for example, the machine may be constructed the way that it is automatically stopped when the produces the defective parts;

3) Varus-kagen - term for the situation, which is not a problem yet, but is not perfect either, and ignoring this situation will surely result in the problem.

A new quality of leadership is the ability to "hear" proposals on improving coming from the regular employees. It is important to understand that no one knows the working process as thoroughly as the exact workers. This allows them to make proposals to rationalize the process and reduces the amount of inefficient operations and wasteful expenditure. In addition, a new quality of leadership is to understand what is necessary to improve the processes and controls and not only to give an immediate economic impact. In the practice of Western management, proposals on improving not profitable in the short term do not always find understanding from senior management. Refusing improvements without momentary economic confirmation, the head reduces the competitive position of their company in the long term.

A new quality of leadership is that the leader should attend to «Gemba» much longer than his own desk. «Gemba» - is a place in the company where all operating activities actually take place. This allows leader to avoid the subjectivity of the information provided. 
With this principle linked with the principle of the processing thinking, according to which, reaching a result, one shouldn't forget about the process of achieving it. It should not only seek to obtain the desired cost parameters, but also improve processes in various areas of the organization in order to obtain better results.

Eliminating stereotypes means a new way of thinking within the kaidzen reflecting a reasonable fight against common points of view. For example, the idea that expensive equipment must work all the time in order to pay off the costs incurred. In practice, this will lead to overproduction, overstocking, the costs of storage inventories, and the increased overhead costs, or the idea that increasing production positively characterizes the analyzed company. In reality, it is necessary to compare the production volumes to the extent required by customers and buyers to conclude which of the situations arose: overproduction and overstock or the confirmed expansion of effective demand.

The principle of control of the deviations from the standard process reflects another feature of kaidzen, controlling the deviations from standard processes. No matter what feature shows the signs of deviation (positive or negative). If the deviation occurred, it requires urgent measures and analysis of the situation. In accordance with the ideology of Toyota, «We decided to make every effort to ensure the control of abnormality», «if all goes well, the control is not necessary» (Davydova, 2012 \& Kireyeva, 2013).

The principle of dynamic tools and targets change considers two aspects:

1) Static position of the plan tasks provides a sharply negative effect on the development of the company. In accordance to ideology of Toyota, plans are being created in order to be changed. If the plans require multilevel and long-term coordination, targets are no longer appropriate for the specific market conditions - which will obviously lead to a mismatch between the consumers' requirements and the company's capabilities.

2) Kaidzen insists on using the latest developments and the application of various combinations of instruments (taking into account the specific situation), the synthesis of different instruments.

The principle of identification and personalization is highlighted in the works of Krishtal M.M. and Zaitseva N.A. (National Standard of the RussianFederation.Management forthe sustained success ofan organization.Approachbased onthe quality managementof GOST R ISO9004-2010: approved and putinto effectby the order of Rosstandart from23.11.2010 №501-st) and represents the need of personal responsibility of the employee for the operation in progress, as well as product identification (previously - the stigma of famous masters, now - trading system marks).

The principle of «baton» is a clear coordination and the availability of clear rules of interaction of employees.

Kaidzen's functions are as follows:

1) Eliminating the stagnation (counter entropy).

The increase in entropy is inevitable with the use of the most advanced forms of management. Its manifestations can be expressed in the deterioration of the starting position, or different from the expected accomplishments in the implementation of innovations. Thus, for the improvement of the mechanisms it is necessary to pay attention not only to quantitative but also qualitative improvements. Supporting actionbs are as important as the achievements of scientific and technological revolution.

2) The balance between the maintenance and improvement.

Maintenance - are actions aimed at keeping current technological, managerial and organizational standards at the needed level; improvement - is the kind of activities aimed at enhancing the existing standards. In other words, it is a balance between process kaidzen and breakthrough kaidzen.

3) Countering the inertial thinking. One shouldn't be complacent during achieving perfection, each stop here - is the first step into stagnation.

4) Development of creative potential. It should be guided by the following thesis: "The procedure exists for a man, not otherwise." Owners do not have to level the creativity of staff, aimed at improving operations.

5) Fleshing techniques. The declared purpose without the methodical study of the necessary tools - is just a slogan that will benefit no one.

6) Synergy.

According to modern economic dictionary, synergy - is the increase of the efficiency of the resulting compound, integration, merging parts into a single system at the expense of so-called systemic effect.

In considering the elements of kaidzen from the position of its structure, I would like to highlight two basic elements: controlling (in the context of the synthesis of management accounting and analysis), and lean production (providing a unified system of quality management and process approach).

Formation of the structure of kaidzen is necessary due to the fact that in modern economic literature in the context of kaidzen improvement of all aspects of the often treated as a tool for other systems:

1) Lean production (such an approach is typical for the works of Vladykina A.A., J. Womack., Davydova N.S., Jones, D., A. Kaminskas, Kizima A.A., Y.P. Klochkova, S. Savvidi M.); 
For example, talking about the benefits of the introduction of lean manufacturing, D. Jones and John Womack noted that «a striking effect on its implementation arises from the radical improvements (kaykaku) of the value creating stream. Then the processes of continuous improvement (kaidzen) that move a company to excellence has gradually come into play» (Detmer, 2013).

A. Kizim gives kaidzen as the part of the composition of elements of such concepts as:

- Lean;

- Six Sigmas;

- Lean plus Six Sigmas (Krishtal, 2010).

2) Innovation Strategy (Management of the organization. Guidelines for Quality Planning: GOST R ISO100052007);

3) Benchmark (special administrative procedure implementation in practice of the organization of technology, standards and methods of work of the best organizations analogues (20).

In our view, these interpretations reflect only few aspects of kaidzen and do not give due to the scale of the system.

Kaidzen allows Lean (management) to impose on controlling to obtain the required rate of return under the dominant influence of three factors: technology, competition, customers.

In accordance with the opinion of James Womack and Daniel Jones, lean production - is a process that includes the definition of customer value, building a consistent stream of values, ensuring the continuity of this flow, providing «pull» from the customer down the process, the pursuit of excellence.

The system of organization of lean manufacturing enterprise involves the creation of adaptive and flexible system of management and production, capable of continuous improvement. The objectives of lean manufacturing are the reduction of costs, including labor, shortening product development, shortening product creation, reduction of production and warehouse space, guarantee product delivery to the customer, the best quality at a certain value or the minimum value at a certain quality.

Lean Kaidzen as an element includes a quality management system and process approach to management.

With the introduction of the concept of lean manufacturing needs change from quality control to quality management, i.e. embedding quality processes. For Japan, characterized by quality control processes, which is clearly prevails over the quality control of production (promotes accountability for the quality of the direct executor).

Process-oriented approach to management considers the business entity as a network of interconnected business processes, each business process is a flowchart aimed at achieving a certain result. In implementing this approach in the management the result orientation is the main importance, i.e., for each business process we know what must be done in order to achieve the desired result.

According to Uvarov P.O., the results of a business process are:

1) Information (industrial and financial) necessary for planning, management and control of investment and industrial and commercial activities of the organization.

2) Management reporting, bringing together natural, cost and financial results in the required sections and appropriate level of detail.

3) Forms of accounting indicators that reflect the organization's activities on capital construction and commissioning.

4) Plans and budgets confirmed and approved by the organization's leaders.

5) Planning and operational documents regulating organization`s cash flows.

6) Internal audit plan of financial and economic activities in the reporting period.

7) Reports on the results of scheduled and unscheduled audits of financial and economic activity (23).

Toolbox controlling and lean production are rather difficult to differentiate. Any attempt of this division is but a formality. Tools of the lean production in different sources are grouped differently. The main basis here is the submitted structuring of the lean manufacturing tools provided by the authors Davydova N.S., Klochkova Y.P. (Detmer, 2013).

According to Davydova N.S., Klochkova Y.P. in the tool group "technology involving" should include kaidzen, which, in our opinion, is methodologically wrong, because it is contrary to the spirit and scale of the system.

Lean Tools:

I. Technologies of analysis:

1) $3 \mathrm{MU}$ - checklist of kaidzen`s actions with three check points: muda (loss), Muri (overload, uneven work with stress), mura (inconsistency, unreasonableness, any deviation from the process).

2) $5 \mathrm{~W}$ (Who? What? Where? When? Why?) - $1 \mathrm{H}$ (How?) (classic version) Who (eg who should perform this operation, who commits it now, and so on.) that (for example, what should be done, is being done, 
and so on.); where (for example, where it should be done, where else one can do, and so on.); when (for example, when to do it, even when it can be done, and so on.); why (for example, why it should be done, why it should be done here and now, and so on.); how (for example, how to do it, whether one can use this method elsewhere, and so on.).

3) Five whys (five-why): the question of "why" five times consecutively given to receive a reply; each time, answering the question, it is easy to determine the true nature of the problem, often hidden behind more obvious reasons (Potemkin, 2010 \& Karepova, et al, 2015).

4) $4 \mathrm{M}$ (sometimes with the addition of $5 \mathrm{M}$ position "Measurement»): «Man» - operator (does he follow the standards, does he have the qualification, does he strive for perfection, and so on.). Machine (Equipment), Material (material), Operationmethod (method of operation).

5) VSM - Value Stream Map shows how to create a product or service and what the costs are incurred. On the map it is possible to classify the flow steps, they either add or don't add value to the customer.

6) TOC - Theory of Constraints E. Goldratt - analysis, involving the use of methods and tools for identifying and eliminating "bottlenecks" of the process, which allows to find an explanation of visiting restrictions in the system and gives guidelines for their elimination.

7) 5 S: 5 steps: a) Sayre (already ordered) - determine the necessary and the superfluous and get rid of the useless (products, equipment, documents, etc.). b) seyton (bring things in order); c) Says (move cleanliness in the workplace); d) seyketsu (personal cleanliness) - the process of change should begin with itself (neat and tidy); d) sitsuke (discipline) - follow the rules work in the unit.

II. Technologies of development:

1) TPM - a set of methods designed to ensure that the machine was kept in working condition, and the production was not interrupted, it provides a reasonable reduction in the time to care for the equipment;

2) SMED - changeover time reduction through a competent organization of work in which most of the operations related to the changeover (internal) are transferred to external (when the equipment works, i.e. works before or after the changeover);

3) JIT - a system in which products are produced and delivered exactly the right time and in the right quantity. The system of "just in time" system becomes "just in time" in the case when the previous operation is completed in a few seconds or minutes before the start of the next operation;

4) Kanban:

- The tool by which coordinated movement of goods.

- Automatic means of information transfer that produce, when, in what amount, manner, and then how it is transported.

- Card, which is attached to the container for the organization of «pull» through information that is necessary to begin the work.

- A special card that was used to inform the provider about the need to start the production or supply of parts to the customer.

- In-plant system, which allows minimizing the duration of the production cycle, from production units to eliminate the logistics system storage of raw materials, components, finished products and to reduce to the minimum possible amounts of interoperable stocks.

5) Poka-Yoke - a special device or method by which defects simply do not occur. One of its manifestations is automation (the introduction of human intelligence in machines capable of independently discovering the first flaw, then immediately stopping and signaling for help) (Detmer, 2013).

6) Target costing - a tool to control and reduce costs at the design stage of construction of the object through the use of industrial, engineering, research and development, it brings together the efforts of all employees in order to achieve the target cost of the project (Chaika, 2006).

III. Technology of involvement:

1) TQM (CWQC) - total quality management (quality management across the company);

2) Hoshin kanri - a method of sharing knowledge, assuming the team focuses on specific issues requiring joint actions of the team members for the project.

3) A method of developing a strategy by top management when resources are directed to those goals that are critical to business (selected from three to five key objectives).

4) Visual inspection - such placement tools, parts, and production indicators of the state in which each first sight can understand the state of the system (transparency).

5) Standardization - the rules and procedures established by the leadership for critical business processes 
that enable employees to successfully carry out their functions.

The reduced scale makes it necessary to divide the manufacturing operations into categories (Davydova, 2012):

1) Actions, creating the added value, during which there is a physical transformation of raw materials into a finished product.

2) Actions that do not create added value, but necessary due to the existing control system (eg, quality control).

3) Actions that do not create added value (assuming the impossibility of referring to any of these two categories) demanding to be taken care of.

When considering the structure and content of submitted instruments one must remember the dynamism of economic realities. Tools are rapidly modified, integrated with each other. An example can be regarded as a comprehensive development of the «Lean Six Sigmas Plus». Six Sigmas is a tool of American design, but by focusing on the customer and quality as well as process approach, it is successfully integrated with the concept of «lean manufacturing».

Obviously, not all the tools are being considered, their variety is due to significant advances in the field of quality management.

With respect to controlling instrumentation it should be noted that the structuring can be selected by one of the following criteria:

1) Time interval (focus on the strategic and tactical tasks) (2);

2) Area of economic knowledge (statistical tools, tools of management accounting with separation into separate groups operating time marketing and management analysis, etc.);

3) Management influence: the cycle of the supply chain (provision, manufacture, sales, etc.); resource (labor, material, etc.). (22).

Grading method does not affect the practical value of the instruments used. According to Prof. Demina E.V., all concepts of modern management have largely the same content but differ in their emphases, terminology, and degree of orientation on certain aspects of management (Imai, 2013).

There are, in particular, the following tools:

1) The method of cost accounting functions (ABC) - a method of determining and accounting costs by type of activity, the method of calculation of operational costs.

2) The standard cost in conjunction with budgeting (the essence of the system is not so much in terms of deviations from targets, as in the formation of perpetrators).

Planning and Budgeting within kaidzen has its own thews.

Kaidzen system is particularly configured for complete elimination of defects. At the initial stage of its implementation their complete absence it is not possible. There are three alternative points of view:

- Defects are not planned, since negative effects cannot be part of the planned targets.

- Defects are not planned, since all automation and control are aimed at preventing them (in particular, introducing automation with human intelligence: stop at the defect).

- Defects are planned as part of the technology due to low standards.

Selecting one of the positions is part of the mentality of the organization management.

In that case scheduling algorithm in a kaidzen is as follows:

- A production plan of the company is made only for the final stage of the process.

- The following process applies to the previous one of the required raw materials, which leads to the production target of the previous process step for the next period (i.e. produce only the required amount plus a minimum margin).

- The most important goal of management is to achieve uniformity of the process (i.e., timely response to the ups and downs that will eliminate sudden changes in the volume of production).

- Bonus Fund should not be focused on the over-fulfillment of the plan in the conditions when over-fulfillment results in unsustainable production assets and the growth of overhead costs, and to a violation of the process or reduction of the quality.

- Formation of the classification of the justified and unjustified costs; while unnecessary costs - the costs that may be excluded in the implementation process without compromising its quality characteristics.

- Rejection of the concept of static policy plans, the rate of change targets must comply with market dynamics.

In accordance to GOST R ISO 9004-2010 «National Standard of the Russian Federation. Managing for the stable success of the organization. An approach based on quality management» in the planning process one should take into account the following points:

- An analysis of the organization`s interior and exterior environment. 
Short-term and long-term forecasts of market trends.

The needs and expectations of stakeholders.

Objectives to be achieved.

Juristic and regulatory requirements.

The potential financial and other risks.

Input and output of the processes, interaction with other processes.

Resources and information, operations and techniques.

Required records.

Measurement, monitoring and analysis.

Corrective and preventive actions, improvements and (or) innovations.

3) The balanced performance indicators (BSC) is designed to evaluate the activity, it is focused on strategic business indicators, taking into account factors of not only internal but also external environment, as well as not only quantitative but also qualitative indicators.

Evaluation conducted in four aspects: the financial aspect, customer, internal business processes, opportunities for development and growth. This control method includes translating strategic objectives into concrete actions and to assess their results by using key performance indicators.

4) Calculation of environmental costs - takes into account the selection of suppliers, whose philosophy and practice of interaction with the environment alongside the technology and practices of buyers, as well as recycling of waste during the manufacturing process, refer to after-sales services, the withdrawal of the product from the market and utilization.

5) Benchmarking (reference evaluation) - a way of gathering information used by organizations to identify best practices of other companies.

6) The system of 20 keys - a tool for evaluating the performance of the company, including a combination of different methods of implementing continuous improvements and enhancements introduced leading companies. In other words, it is a benchmarking tool, by which the process of research and evaluation of the effectiveness of the company is greatly simplified.

Under this system, the company estimates its own organization with 20 keys (each of which - a factor that is critical to its operation) on a 5-point scale. By determining the level at which the company is located in each of the 20 keys, identified its weaknesses. For example: 1 - cleanliness and organization; 2 optimization of management objectives, 3 - work of the team to introduce improvements; 4 - reduction of stocks and time to execute the order and so on.

7) Advance Product Quality Planning (APQP) - a structured method of defining and timely implementation of all phases of work required to meet the demands and expectations of consumers.

8) Critical Path Method (CPM) - project management method, used in network planning, to identify, outline and analysis of the sequence of work, cost and duration of the project, necessary for its completion.

9) Analysis based on the model Shell / DPM is based on the fact that the overall strategy of the organization should ensure the maintenance of a balance between cash surpluses and deficits.

The greatest effect is the combination of several tools. According to Safronova C.F. good result is achieved through the interaction of the Kanban + Just-in-Time, TPM + SMED, LeanManufacturing + SixSigma, TQM + ISO: 9000 (21).

\section{Results and Discussion}

It's worth remembering that there are no universal methods, techniques, tools that would be useful in every situation. An important role in the background of considerable erudition in economic disciplines goes to the ability to choose the tools (techniques and methods), taking into account the specifics of the situation, the characteristics of the market, the characteristics of the company and the product. Conceptual ability (the ability to perceive the relationship between the organization and the environment and to see the system of the organization as a whole) and the personal qualities of managers are more important than technical skills.

The Russian organizations use tools kaidzen in fragmented manner. Therefore, for the successful implementation of this system it is necessary to ensure comprehensive implementation and emphasize the philosophy of kaidzen as a way of thinking, especially CEOs.

Thus, in the present study terminological field was structured in the context of the general theoretical, structural and methodological elements of kaidzen. 


\section{References}

Womack, J.Lean (2014) Thinking: Banish waste andcreatewealth in oner corporation/J.Womack, D. Jones; Translated from English.M.:Alpina Publisher, pp. 472.

Davydova, N.S. (2012) Management modelof "Lean" enterprise'sImplementation /N.S. Davydova, P.Y.Klotchkov//Bulletin of Udmurt University. Vol.4. pp. 32-35.

Demina, E.V. (2010) Proposals forthe lossof value determiningto theconcept oflean manufacturing/E. V.Demina, E.B. Milinkis, S.E. Milinkis// T-Comm:Telecommunicationsand Transportation. T.4. № 12. pp. 57-59.

Detmer, W. (2013) Goldratt's Theory of Constraints: A systems Approachto continuous improvement/W.Detmer; Translatefrom English.M .:Alpina Publisher, pp. 443.

Imai, M. Kaidzen (2013) The Key to Japan's Competitive Success / M. Imai; translated from English. - M.: Alpina Publisher. pp. 274.

Novikov, V.S., Klochko, E.N., Yarushkina, E.A., Zhukov, B.M. \& Dianova, V.A. (2015) On peculiarities of the virtual economy of modern Russia: categories, virtual relationships, educational constructs. Mediterranean Journal of Social Sciences, 363 (247-257).

Kanban and "just in time" at Toyota: management begins at the workplace / translated from English (2014). M.: Alpina Publisher. pp. 214.

Kobersy, I., Barmuta, K., Muradova, S., Dubrova, L., \& Shkurkin, D. (2015). The System of the Methodological Principles of Management of Enterprise Development. Mediterranean Journal Of Social Sciences, 6(3 S4), 25. Retrieved from http://www.mcser.org/journal/ index.php/mjss/article/view/6707

Kizim, A. (2012) Integrationof logisticstools inthe concept of "lean production" IA.Kizim,A.Berezovsky//Logistics. № 3. pp.56- 59.

Kireyeva, N. (2013) Innovative mechanisms of logisticsmanagement tools/N.Kireyeva//Logistics. № 1. pp. 38 -39.

Krishtal, M. (2010) Specific character of "lean production"introducing indomesticconditions/M.M.Krishtal, N.A. Zaitseva//Vector of ScienceTSU. №3(13). pp. 158 -160.

Management of the organization. Guidelines for Quality Planning: GOST R ISO10005-2007: approved by Order of Rostechregulirovanie from 27.12.2007№567-st

National Standard of the RussianFederation.Management forthe sustained success ofan organization.Approachbased onthe quality managementof GOST R ISO9004-2010: approved and putinto effectby the order of Rosstandart from23.11.2010 №501-st

Potemkin, A.I. (2010) Japanese"kaidzen" and creative activity ofRussianworkers/A.I.Potemkin, N.V. Morgunova, N.M. Filimonoval/ Russian Entrepreneurship. №8 (1). pp.41- 45.

Karepova, S.G., Karabulatova, I.S., Klemovitsky, S.V., Novikov, V.S., Stratan, D.I. \& Perova, A.E. (2015) New approaches to the development of methodology of strategic community planning. Mediterranean Journal of Social Sciences, 363 (357-363).

Raizberg, B.A. (2008) ModernDictionary of Economics/B.A.Raizberg, V. Sh.Lozovskiy, E.B. Starodubtseva. M: INFRA-M. pp. 512.

Beloglazov Denis, A., Finaev Valery, I., Zargarjan Jury, A., Soloviev Victor, V., Kosenko Evgeny, Y., \& Kobersy Iskandar, S. (2015). Efficiency of genetic algorithms in intelligent hybrid control systems. ARPN Journal of Engineering and Applied Sciences, 10(6), 2488-2495.

Uvarov, P.O. (2012) Management accounting of investment and construction activities/P. O.Uvarov//Microeconomics. № 6. pp. 62-65.

Chaika,V.A. (2006) Principles of quality's continuousimprovement in Russian companies/V.A.Chaika// Bulletin ofSt. Petersburg University. Management. № 2. pp. 43-64. 